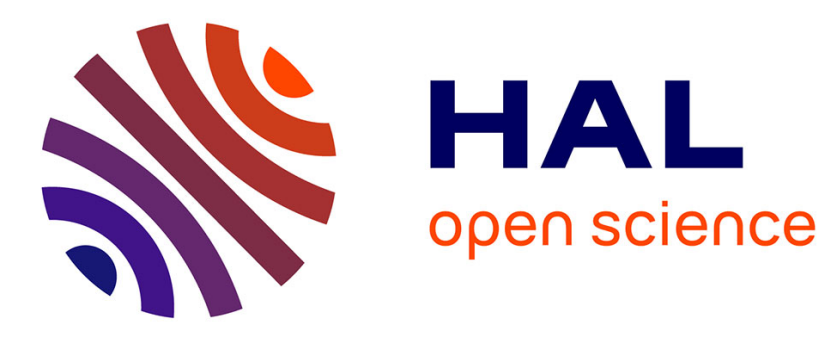

\title{
Physicochemical and Accelerated Aging Tests of Metglas 2605SA1 and Metglas 2605HB1 Amorphous Ribbons for Power Applications
}

\author{
Malick Mouhamad, Christophe Elleau, Frederic Mazaleyrat, Christian \\ Guillaume, Bertrand Jarry
}

\section{To cite this version:}

Malick Mouhamad, Christophe Elleau, Frederic Mazaleyrat, Christian Guillaume, Bertrand Jarry. Physicochemical and Accelerated Aging Tests of Metglas 2605SA1 and Metglas 2605HB1 Amorphous Ribbons for Power Applications. IEEE Transactions on Magnetics, 2011, 47 (10), pp.3192-3195. 10.1109/TMAG.2011.2158295 . hal-00661842

\section{HAL Id: hal-00661842 https://hal.science/hal-00661842}

Submitted on 20 Jan 2012

HAL is a multi-disciplinary open access archive for the deposit and dissemination of scientific research documents, whether they are published or not. The documents may come from teaching and research institutions in France or abroad, or from public or private research centers.
L'archive ouverte pluridisciplinaire $\mathbf{H A L}$, est destinée au dépôt et à la diffusion de documents scientifiques de niveau recherche, publiés ou non, émanant des établissements d'enseignement et de recherche français ou étrangers, des laboratoires publics ou privés. 


\title{
Physicochemical and Aging Tests of 2605SA1 and 2605HB1 Amorphous Ribbons for Power Applications
}

\author{
Malick Mouhamad $^{1}$, Christophe Elleau ${ }^{1}$, Frédéric Mazaleyrat ${ }^{2}$, Christian Guillaume ${ }^{1}$ and Bertrand Jarry $^{3}$ \\ ${ }^{1}$ EDF R\&D, Laboratoire des Matériels Electriques, Moret sur Loing-77250, France \\ ${ }^{2}$ SATIE, ENS Cachan, CNRS, Universud, Cachan-94230, France \\ ${ }^{3}$ ERDF DFI, Tour Winterthur, Puteaux-92085, Paris La Défense, France
}

\begin{abstract}
To evaluate the physicochemical compatibility of rapidly solidified ribbons with transformer insulating fluids, isothermal heating process was carried out in order to prove the sustainability of these materials. Fe-based amorphous ribbons were immersed in mineral and vegetable transformer oils for a period of 580 hours at 110 and $140^{\circ} \mathrm{C}$. Chemical analyses of oils after experimentation have shown absence of amorphous alloys' components such as $\mathrm{Fe}$, Si and $\mathrm{B}$. In addition, a stability of magnetic properties is witnessed via the measurements of iron losses. Moreover, X-ray diffraction patterns of ribbons after aging experiments reveal a fully amorphous structure. Calculated lifetimes from accelerated aging test show a good stability of amorphous ribbons in field conditions.
\end{abstract}

Keywords - Amorphous alloys; Accelerated aging; Iron losses

\section{INTRODUCTION}

The transformers installed in electricity distribution grid are extremely efficient when compared to other machines. The efficiency of distribution transformers can exceed $99 \%$. Despite the high efficiency of individual units, losses occur at each transformation steps in an electricity supply network. The overall losses in EU-27 distribution transformers are estimated at 33 TWh per year [1]. Energy losses in distribution network can be mainly divided into no-load losses, which probably account for about $63 \%$ of total losses. The potential for reducing losses from distribution transformers is considered as one element of EU and national strategies on energy efficiency, global warming and environmental impact. Considering the potency of losses generated in transformers, ERDF, French national distribution company, has decided to reduce them in order to fulfill EU policies and its environmental commitment.

The energy efficiency of a distribution transformer, in terms of losses, is fundamentally dependent on the type of material used for building the transformer core. Recent developments in magnetic core materials have led distribution utilities to reduce their no-load losses. Especially, amorphous ribbon units represent a significant new advance in transformer technology. Amorphous core distribution transformers allow more than $60 \%$ reduction in no-load losses compared to conventional grain oriented silicon steel transformers [2]. Under the present environment of high energy costs and concerns for climate change, ERDF is working to improve its distribution system efficiency and focusing on employing efficient transformers, such as amorphous units. European experience of manufacturing and installing amorphous designs in the EU has been very limited [3]. Amorphous metals have been used in distribution transformer cores for a long time in the US, Japan, India and China [4].

This paper deals with the physicochemical compatibility and aging tests of amorphous ribbons. These investigations will verify if these soft magnetic amorphous ribbons, intended for distribution transformer cores, maintain a long-term performance compared to traditional magnetic cores.

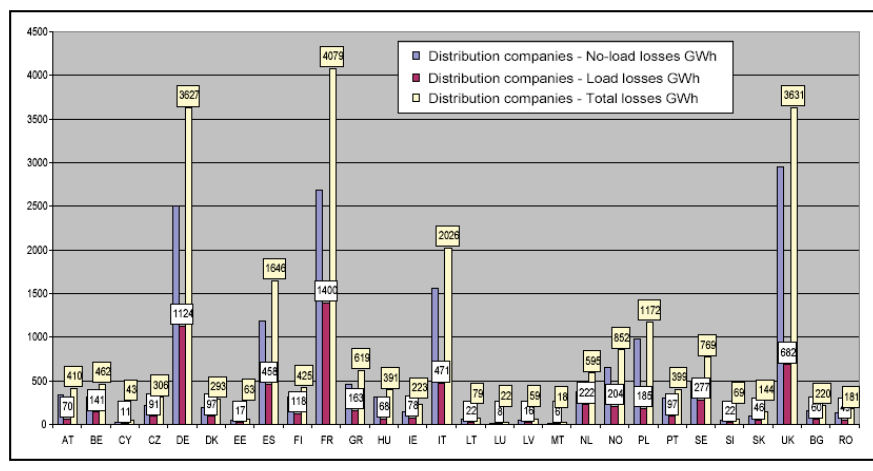

Fig. 1. Breakdown of distribution sector distribution transformer losses, EU27 and Norway [1].

\section{MATERIALS AND EXPERIMENTAL PROCEDURES}

Fe-based amorphous 2605SA1 and 2605HB1 materials were prepared by melt spinning method and provided by Hitachi Metglas. The dimensions of the ribbon samples used for magnetic measurements were $23-25 \mu \mathrm{m}$ in thickness, 10 $\mathrm{mm}$ in width and $80 \mathrm{~mm}$ in length. Metglas ${ }^{\circledR} 2605 \mathrm{SA} 1$ and $2605 \mathrm{HB} 1$ were first annealed at 350 and $320^{\circ} \mathrm{C}$ in an argon atmosphere for 5 hours. The iron loss measurements were carried out at $50 \mathrm{~Hz}-1.25 \mathrm{~T}$ with a single sheet tester (SST). Xray diffraction (XRD) patterns were recorded using Rigaku Geigerlfex diffractometer, equipped with a primary monochromator. The radiation employed for the measurements was $\mathrm{Co} \mathrm{K} \alpha(30 \mathrm{kV}, 37.5 \mathrm{~mA})$. Aging investigations were carried out in a tubular furnace with argon atmosphere.

RESULTS AND DISCUSSIONS

In this section, physicochemical and aging test results will be presented and discussed.

\section{A. Physicochemical compatibility}

To investigate the physicochemical compatibility of amorphous ribbons, an isothermal heating process was carried out with these materials in insulating fluids at $110^{\circ} \mathrm{C}$ and 
$140^{\circ} \mathrm{C}$. Both temperatures represent the maximum temperature that transformers reach at 100 and $150 \%$ loading according to ERDF specification. This heat treatment consists of quenching amorphous ribbons in transformer oils for a certain period of time. One sample, after certain soaking period, was taken out and measured with SST. In this manner, the evolution of iron losses in time for each alloy is established. Fig. 2 shows the iron losses of $2605 \mathrm{SA} 1$ and $2605 \mathrm{HB} 1$ alloys tested at $140^{\circ} \mathrm{C}$ versus soaking time.

Our results show the newly developed 2605HB1 alloy has lower core losses than 2605SA1 alloy. The magnetic properties of $2605 \mathrm{HB} 1$ material were previously studied by Dr. Hasegawa [5]. It is worth mentioning that our results show the same trends as the results obtained by Dr. Hasegawa as far as the magnetic properties of $2605 \mathrm{HB} 1$ are concerned.
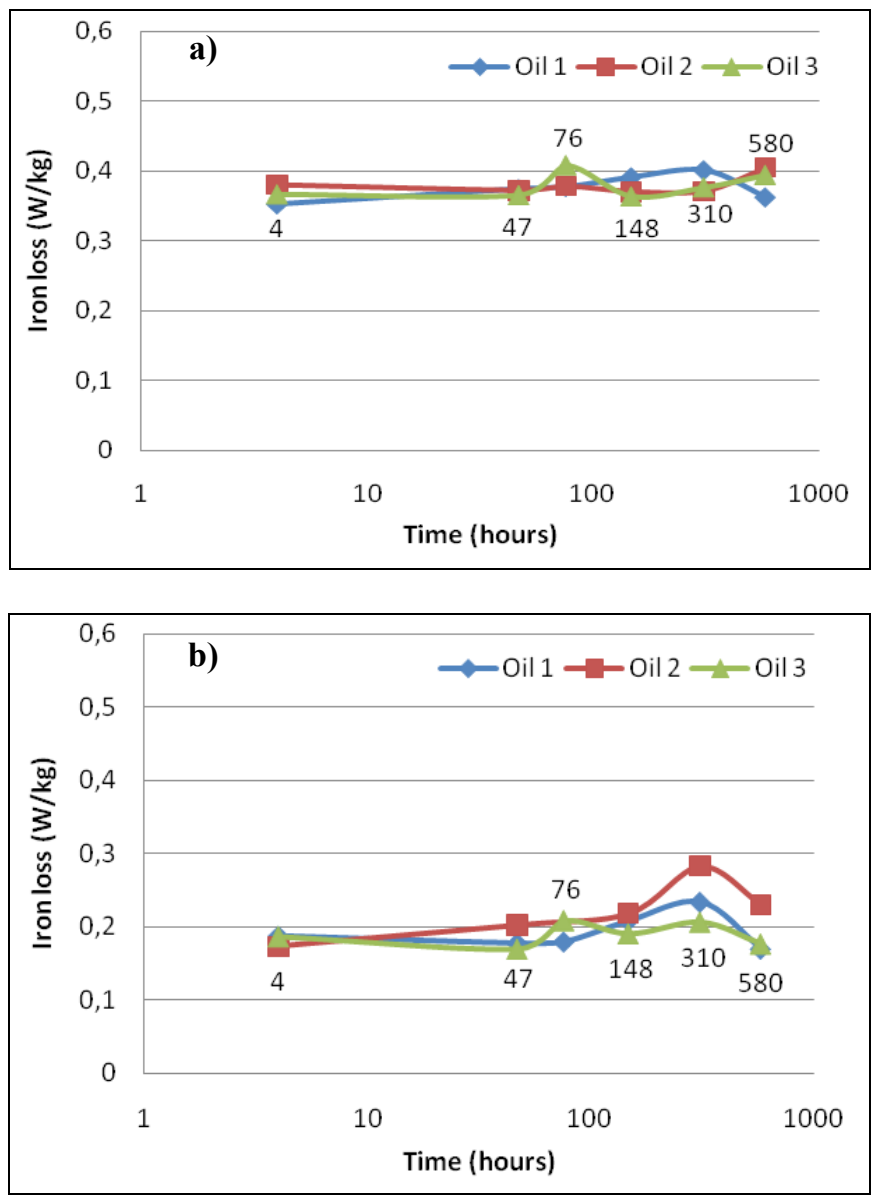

Fig. 2. Evolution of iron losses of a) 2605SA1 and b) $2605 \mathrm{HB} 1$ amorphous ribbons at $140^{\circ} \mathrm{C}$. Materials were heated for $4,47,76,148,310$ and 580 hours as reported above. The time period axis is given in logarithmic scale.

From Fig.2, it is shown that the iron losses of both alloys are steady. For example, the iron loss of 2605SA1 varies between 0.35 and $0.4 \mathrm{~W} / \mathrm{kg}$ throughout the whole aging process. The same behavior is also witnessed in 2605HB1 alloy where the iron loss fluctuates in the gap of $0.15-0.25$ $\mathrm{W} / \mathrm{kg}$. The materials were tested in extreme heating conditions (at $140^{\circ} \mathrm{C}$ for 580 hours), yet the core losses of 2605SA1 and
$2605 \mathrm{HB} 1$ are less wavering. The same trend is observed at $110^{\circ} \mathrm{C}$. This stability in iron loss proves that insulating fluids do not have an impact on magnetic properties of amorphous alloys. The small variation witnessed is mainly due to experimental inaccuracy during the calculation of iron losses from analytical B-H curves.

The physicochemical compatibility tests were done in intense heating situations. Thermal study should be carefully handled with amorphous materials because the amorphous structure is in a metastable state. Thermal energy and chemical interaction contributions could transform the amorphous structure into crystalline phase. Therefore, XRD study is required to identify the structure of tested amorphous materials. Fig. 3 represents the diffraction patterns of tested $2605 \mathrm{SA} 1$ and $2605 \mathrm{HB} 1$ ribbons at $140^{\circ} \mathrm{C}$ in insulating fluids.
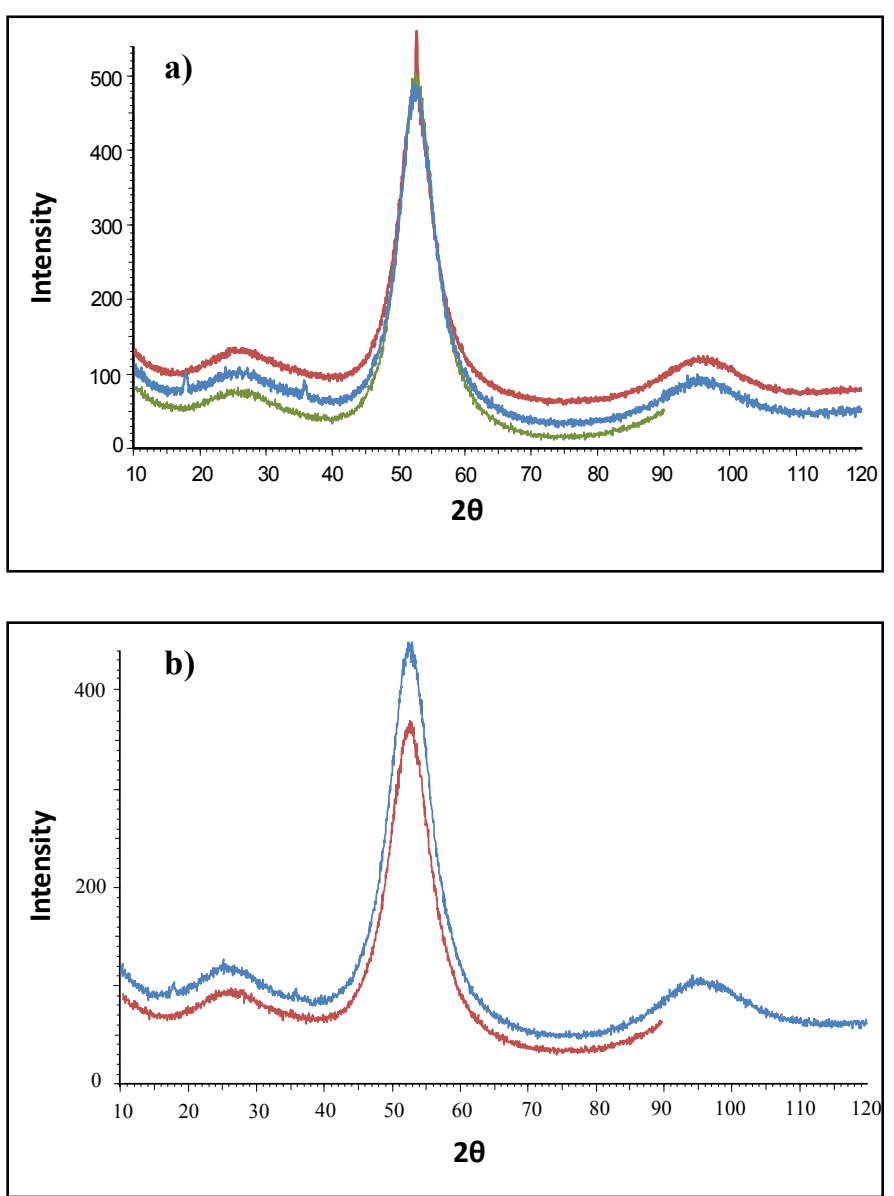

Fig. 3. Results of X-ray diffraction of a) $2605 \mathrm{SA} 1$ and b) $2605 \mathrm{HB} 1$ ribbons at $140^{\circ} \mathrm{C}$ in following insulating fluids: Oil 1 - Oil 2 - Oil 3.

The patterns were slightly adjusted for a better comparative presentation. The $\mathrm{X}$-ray diffraction for HB1 quenched in Oil 3 were not recorded for technical reasons.

All the samples consist of an amorphous phase indicated by the broad hump in the diffraction patterns at around $2 \theta=55^{\circ}$ and the absence of crystalline peaks. It should be noted that a peak is noticed for the 2605SA1 sample immersed in Oil 2 and 2 small peaks for samples soaked in Oil 1 . The first one is indexed to $\alpha$-FeSi phase and this phase was already present in the alloy before the investigations. During melt-spinning, due 
to impurities on the solidifying wheel, small fractions of crystalline phase can be encountered. The 2 peaks identified in Oil 1 are mainly due to the carbonization of amorphous alloys as they were immersed in mineral oil. It should be noted that these peaks are not formed by crystallization of amorphous ribbons in isothermal test. So, it is observed that 2605SA1 and 2605HB1 alloys maintain their amorphous structure in contact of insulating fluids, even in extreme heating conditions.

\section{B. Accelerated aging test}

\section{1) Thermal analysis}

Before starting the aging study, thermal analysis is needed in order to record specific temperatures of aforementioned amorphous alloys. In general, thermal stability of an amorphous material is investigated by Differential Scanning Calorimetry (DSC). Likewise the thermal properties of the samples such as onset crystallization temperature $\left(T_{x}\right)$ and heat were determined by DSC. The measurements were done with a temperature window of $25-600^{\circ} \mathrm{C}$ and a heating rate of $40^{\circ} \mathrm{C} / \mathrm{min}$.

It is known that amorphous alloys exhibit an endothermic heat event of the glass transition followed by characteristic exothermic heat release events corresponding to the successive transformations from a supercooled liquid region to the equilibrium crystalline phases at different temperatures.

Fig. 4 shows the DSC curves of 2605SA1 and 2605HB1alloys. It is found that 2605SA1 alloy presents two exothermic peaks, indicating that this alloy crystallizes through two overlapping heat events. The recorded values of $T_{x}$ and crystallization heat $(\Delta \mathrm{H})$ of the alloys are summarized in Table I. As mentioned earlier, at higher temperatures or longer times of annealing, the glass will crystallize. These values are useful in order to carry out accelerated aging test and to obtain good results.

TABLE I

THERMAL PROPERTIES OF 2605SA1 AND 2605HB1

\begin{tabular}{|c|c|c|c|c|}
\hline Alloy & $\mathrm{T}_{\mathrm{x} 1}\left({ }^{\circ} \mathrm{C}\right)$ & $\mathrm{T}_{\mathrm{x} 2}\left({ }^{\circ} \mathrm{C}\right)$ & $\Delta \mathrm{H}_{1}(\mathrm{~J} / \mathrm{g})$ & $\Delta \mathrm{H}_{2}(\mathrm{~J} / \mathrm{g})$ \\
\hline 2605SA1 & 525 & 568 & 82 & 155 \\
\hline 2605HB1 & 502 & - & 211 & - \\
\hline
\end{tabular}

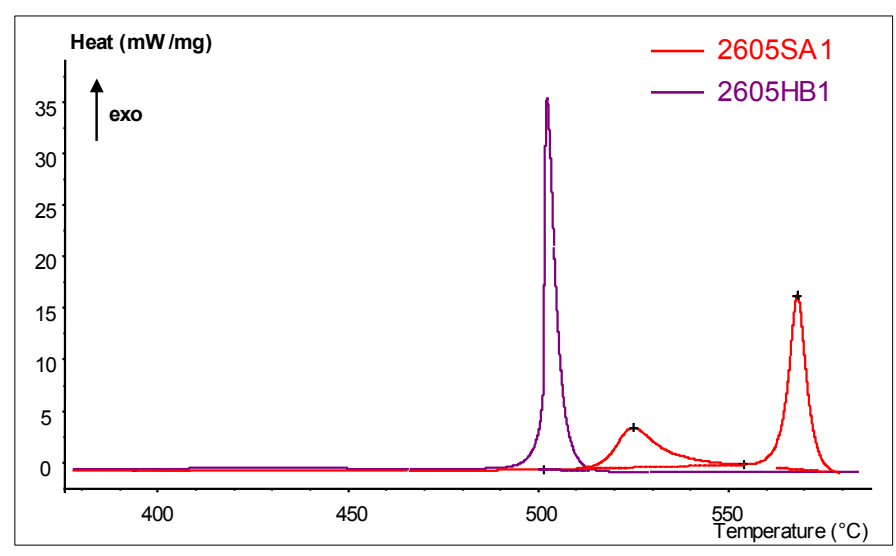

Fig. 4. DSC traces obtained from 2605SA1 and 2605HB1 ribbon samples.

\section{2) Aging study}

This part is dedicated to the evaluation of lifetime of amorphous ribbons. The kinetic transformation of the local atomic structure can be used to estimate it. This structural change can be traced by measuring a magnetic property of the material.

A 10-day accelerated aging test was carried out with annealed 2605SA 1 and $2605 \mathrm{HB} 1$ samples over $260^{\circ} \mathrm{C}$ in order to enhance the structure. Iron loss was chosen as the indicator of structural change.

Between 260 and $300^{\circ} \mathrm{C}$, the iron losses were stable. A regular increase in losses is detected for $2605 \mathrm{HB} 1$ from $350^{\circ} \mathrm{C}$ and from $360^{\circ} \mathrm{C}$ for $2605 \mathrm{SA} 1$. The values of iron losses are plotted below (Fig. 5) as a function of aging time for different temperatures. The aging process of materials is dependent on the coupled Time-Temperature parameter. This factor was analyzed with Arrhenius law (1) for a lifetime calculation of amorphous ribbons.

$\tau:$ time

$$
\ln \tau=A+E a /\left(k_{B} T\right)
$$

A : constant

Ea : activation energy

$\mathrm{k}_{\mathrm{B}}$ : Boltzmann constant

$\mathrm{T}:$ temperature
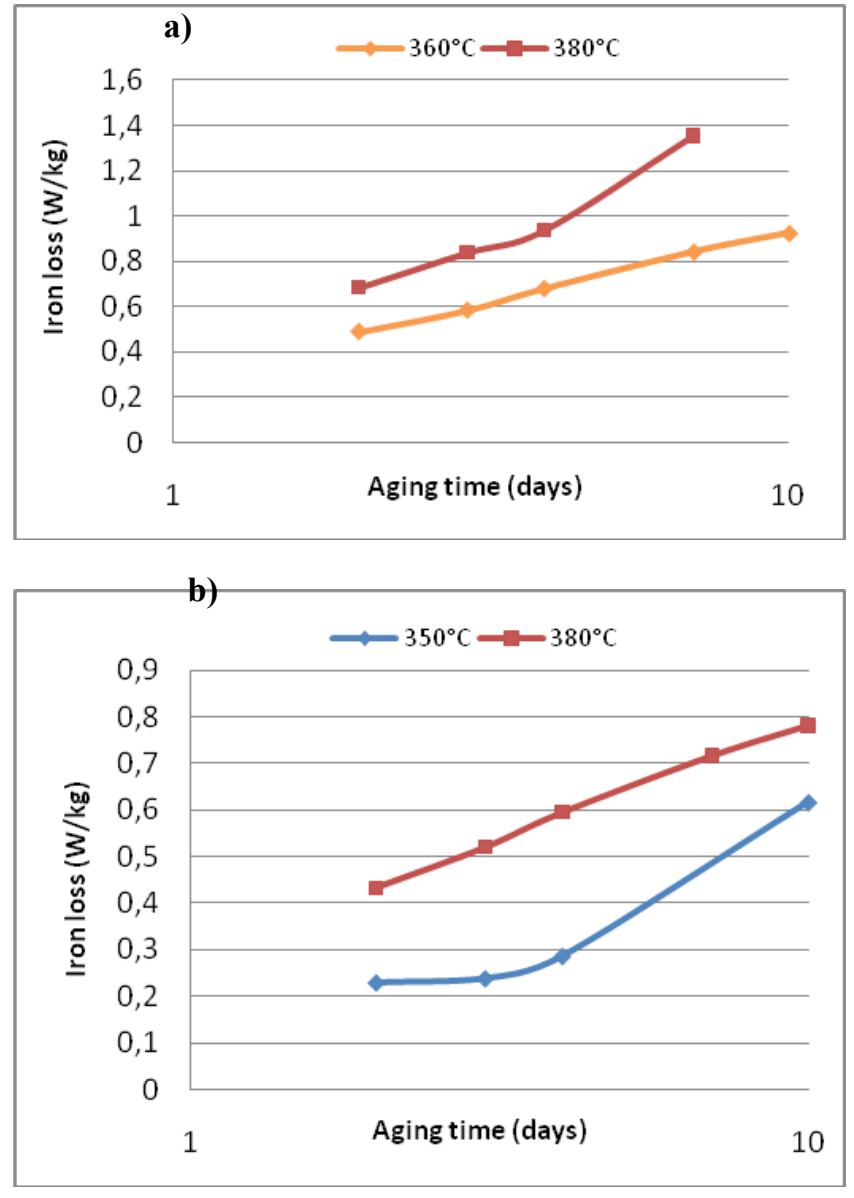

Fig. 5. Evolution of iron losses of aged a) 2605SA1 and b) 2605HB1 ribbons. Materials were aged for 2, 3, 4, 7 and 10 days. The aging time axis is given in logarithmic scale. 
In that purpose, time values in logarithmic scale were plotted as a function of the inverse of the aging temperature for a given iron loss. The estimated lifetime at $150^{\circ} \mathrm{C}$ for $\mathrm{SA} 1$ and HB1 alloys are 7100 years and 600 years. These values are entirely satisfactory regarding transformer requirements.

\section{CONCLUSION}

The magnetic properties of heated amorphous samples were analyzed by the measurement of iron losses. The evolution of these losses showed that they are stable throughout the whole heating process. Furthermore, XRD investigations have revealed that amorphous ribbons keep their structural state. A stability in magnetic properties and the conservation of structural properties show that SA1 and HB1 possess a good physicochemical compatibility with tested transformer dielectric fluids.

Lifetimes of both alloys were estimated through Arrhenius law with results from aging investigations. It should be noted that SA1 and HB1 alloys possess a far longer life than the transformer itself.

The calculated lifetimes and the physicochemical test show these amorphous materials can maintain a long-term performance as a magnetic core in a transformer.

\section{REFERENCES}

[1] R. Targosz, F. Topalis and W. Irrek, "Selecting energy-efficient distribution transformers: A guide for achieving least-cost solutions," SEEDT Project (2008)

[2] H.W. Ng, R. Hasegawa, A.C. Lee and L.A. Lowdermilk, "Amorphous alloy core distribution transformers," Proceedings of the IEEE, vol. 79, no. 11 (1991), p. 1608-1623

[3] B. Jarry, P. Lauzevis, P. Lagache and Michel SACOTTE, "Amorphous sheet core transformers under experimentation on the ERDF network," CIRED (2009), Paper 0090

[4] M. Sampat, "Amorphous metal transformer: Next steps," EPRI (2009), 1017898

[5] Y. Ogawa, M. Naoe, Y. Yoshizawa, R. Hasegawa, "Magnetic properties of high $\mathrm{B}_{\mathrm{s}} \mathrm{Fe}$-based amorphous material," Journal of Magnetism and Magnetic Materials, vol. 304, issue 2 (2006), p. e675-e677 